\title{
ÍNDIOS TICUNAS E A COMPLEXIDADE PARA UMA EDUCAÇÃO NO SÉCULO XXI
}

\author{
SAMUEL ROCHA DE OLIVEIRA* \\ FRANCISCA FRANCIELIS AZEVEDO MAFRA DE OLIVEIRA** \\ IZABEL CRISTINA PETRAGLIA***
}

\begin{abstract}
RESUMO
Este estudo aborda os Índios Ticunas e a complexidade da educação no século XXI, bem como reflete a respeito da educação oferecia aos índios ticunas. A hipótese que sustenta este estudo baseia-se no fato que os indígenas ticunas convivem com a cultura ocidental e precisam de uma visão educacional diferenciada que considere a sua própria cultura, dessa forma estabelecem relações sociais complexas como estratégias de sobrevivência, e são vistos de forma preconceituosa pela sociedade como etnia inferior, nos padrões da cultura do ocidente. Temos três objetivos i) Descrever como ocorre a educação escolar indígena. ii) demonstrar a complexidade da tradição cultural e a relevância da manutenção das culturas indígenas. iii) analisar a complexa relação da Educação indígena e se a educação escolar indígena, instituída na aldeia cumpre a função de formar para vida. O corpus selecionado para este estudo é o repasse cultural dos índios ticunas que habitam o território do Alto rio Solimões no Amazonas.
\end{abstract}

* Doutorando em Educação pela Universidade Metodista de São Paulo (UMESP), São Bernardo do Campo (SP); E-mail: samuel-amazonas@ hotmail.com. http://orcid.org/0000-0002-2183-9564

** Mestre em Educação pela Universidade Metodista de São Paulo (UMESP), São Bernardo do Campo (SP); E-mail: ffam-oliveira@hotmail.com

*** Doutora, professora do Programa de Pós-Graduação em Educação (PPGE) e líder do GEPEC - Grupo de Estudos e Pesquisa em Complexidade da UMESP. E-mail: izabelpetraglia@terra.com.br 
O que justifica essa escolha é a observação que culturalmente para a criança ticuna, as primeiras experienciais da educação são promovidas pela família, entretanto, diversos pais não percebem a importância de sua participação no repasse cultural para a manutenção cultural. É uma pesquisa qualitativa de cunho bibliográfico e descritivo amparadas nos trabalhos de Champlim (1991), Brandão (1995), Gruber (1997) e Morin (2001) dentre outros. Mediante os resultados podemos concluir a oferta educacional para as aldeias, mesmo no formato da educação ocidental, pode contribuir significativamente para o avanço no procedimento para a manutenção cultural dos ticunas, mas é preciso um novo significado para a instituição escolar, que historicamente foram formatadas para negar a diversidade cultural, a escola precisa ser transformada em espaço de construção de relações interétnicas direcionadas a preservação da multiculturalidade.

Palavras-chave: Educação Indígena, Complexidade, Educação Escolar Indígena.

\title{
TICUNAS INDIANS AND COMPLEXITY FOR AN EDUCATION IN THE 21ST CENTURY
}

\begin{abstract}
ABSRACT
This study addresses the Ticuna Indians and the complexity of education in the 21 st century, as well as reflecting on the education offered to the Ticuna Indians. The hypothesis that supports this study is based on the fact that Ticuna indigenous people live with Western culture and need a differentiated educational vision that considers their own culture, thus establishing complex social relationships as survival strategies, and are seen in a different way. prejudiced by society as an inferior ethnic group, according to the standards of Western culture. We have three objectives i) Describe how indigenous school education takes place. ii) demonstrate the complexity of cultural tradition and the relevance of maintaining indigenous cultures. iii) analyze the complex relationship of
\end{abstract}


indigenous education and whether indigenous school education, instituted in the village, fulfills the function of training for life. The corpus selected for this study is the cultural transfer of the Ticuna Indians who inhabit the territory of the Upper Solimões River in Amazonas. What justifies this choice is the observation that culturally for the Ticuna child, the first experiences of education are promoted by the family, however, many parents do not realize the importance of their participation in the cultural transfer for cultural maintenance. It is a qualitative bibliographic and descriptive research supported by the works of Champlim (1991), Brandão (1995), Gruber (1997) and Morin (2001) among others. Based on the results, we can conclude that the educational offer for the villages, even in the format of Western education, can significantly contribute to the advancement of the procedure for the cultural maintenance of the Ticunas, but a new meaning is needed for the school institution, which has historically been formatted for denying cultural diversity, the school needs to be transformed into a space for building interethnic relations aimed at preserving multiculturalism.

Key-words: Indigenous Education, Complexity, Indigenous School Education.

\section{INTRODUÇÃO}

O tema escolhido para este estudo é os Índios Ticunas e a complexidade da educação no século XXI, onde refletiremos sobre o sistema educacional oferecido aos índios ticuna. A hipótese que sustenta este estudo baseia-se no fato que os indígenas ticunas convivem a cultura ocidental e precisam de uma visão educacional diferenciada que considere sua a cultura, dessa forma estabelecem relações sociais complexas como estratégia de sobrevivência, e são vistos de forma preconceituosa pela sociedade como etnia inferior, nos padrões da cultura do ocidente. Temos três objetivos i) Descrever como ocorre a educação escolar indígena. ii) demonstrar a complexidade da 
tradição cultural e a relevância da manutenção das culturas indígenas. iii) analisar a complexa relação da Educação indígena e se a educação escolar indígena, instituída na aldeia cumpre a função de formar para vida.

O corpus selecionado para este estudo é o repasse cultural dos índios ticunas que habitam o território do Alto rio Solimões no Amazonas, cujo território chamado por eles de Eware está localizado na Região do Alto Solimões no Amazonas, distante aproximadamente $1600 \mathrm{~km}$ de Manaus, Capital do Amazonas. Este estudo se justifica pela observação de que culturalmente para a criança ticuna, as primeiras experienciais da educação são promovidas pela família, entretanto, diversos pais não percebem a importância de sua participação no repasse cultural para a manutenção cultural.

É uma pesquisa qualitativa de cunho bibliográfico e descritivo amparadas nos trabalhos de Champlim (1991), Brandão (1995), Gruber (1997) e Morin (2001), dentre outros.

Este artigo apresenta os seguintes tópicos: Os Índios Ticunas do Alto rio Solimões; A Complexa relação de Integrar para Domesticar; A Complexidade e a Importância no Repasse da Cultura: O Imaginário Ticuna, os Mitos e os Fenômenos da Educação; A Complexa relação da Educação Indígena e a Educação Escolar Indígena, os quais procuraremos desenvolver de forma que sejam alcançados os objetivos propostos e procuraremos de forma suscinta descrever os conhecimentos adquiridos com este estudo nas considerações finais. Esperamos ao final do mesmo poder contribuir significativamente para a elevação e conhecimento dos indígenas ticunas bem como apontar possíveis caminhos a trilhar para uma educação no século XXI, referente aos ticunas da região.

\section{OS ÍNDIOS TICUNAS DO ALTO RIO SOLIMÕES}

Os indígenas ticunas habitam no território do Alto rio Solimões no Amazonas, trazem esse nome não como uma autodenominação, mais sim desde épocas remotas os seus ancestrais os apelidaram assim. Conforme Oliveira (2012), provavelmente 
o nome que ticuna teve origem partindo dos indígenas Omáguas, indígenas com quem os Magüta disputavam a Região. O nome Tikuna, cujo significado na língua Tupi Guarani nariz preto, faz menção a pratica cultural de pintura do rosto com o fruto jenipapo verde, para representar as filiações clânicas. Essas pinturas são realizadas pelos ticunas com uma tinta extraída do fruto Jenipapo. O Povo ticuna autodenominam-se nação Magüta, esse termo indígena literal quer dizer "povo pescado" pelo caniço (vara de pesca) por Yo’i, um herói da mitológico na cultura dos ticunas.

A reserva indígena dos Ticunas é o local sagrado Eware localizada na região do Alto Solimões, distante aproximadamente 1600 km de Manaus, Capital do Amazonas. O território possui fronteiras política terrestre com Três países: com o Peru, a Colômbia e o Brasil. O fenômeno intercultural atual permite que os indígenas ticunas pertençam a três países distintos. Assim lutam para reafirmar sua identidade étnica cultural, se adaptando às diferentes manifestações culturais existentes no território do Alto Solimões.

Os indígenas ticunas utilizam os relacionamentos sociais como estratégia de sobrevivência, conforme Oliveira (2012) uma estratégia em que lutam no cerne dos relacionamentos sociais contraria ao que Lévi-Strauss (1993) chama de Cultura original, ficando evidente esse mecanismo por meio dos movimentos indígenas e pelo contato com a fronteira cultural. Observamos, assim, a ressignificação cultural dos ticunas baseado na diversidade de cultural que existem na região e proporciona as relações entre índios e não indígenas nos países que compõem a região.

\section{A COMPLEXA RELAÇÃO DE INTEGRAR PARA DOMESTICAR}

O Estado detentor da tutela indígena não se preocupou em praticar nenhuma política indígena especifica que não fosse as voltadas apenas com vistas a integração. Tanto Antropólogos como linguistas foram convidados a dar parecer sobre os 
diversos convênios firmados organizações, entidades religiosas, entretanto foram deixados de lado antropólogos, linguistas e educadores, para pensar uma proposta educacional para a Educação Escolar indígena atendesse as necessidades. O slogan era integrar indígenas, vistos pelos padrões culturais do ocidente em uma condição selvagem e de etnia inferior. Essa condição é confirmada mediante o órgão oficial que mantinha a tutela, Serviço de Proteção ao Índio - SPI, que passou a chamar-se de Fundação Nacional do Índio - FUNAI, foram estabelecidas diversas parcerias com organizações de diferentes seguimentos religiosos, com a missão de implantarem o sistema o escolar nas aldeias.

Com o passar dos anos, a educação caminhou lado a lado com as religiões e de posturas humanistas e pragmáticas, direcionando a elaboração das políticas indigenistas no brasil, hoje, mediante as conquistas garantidas pela última Constituição referentes a direitos dos nativos, é possível que haja uma oposição entre correntes progressistas outorgadas pela lei e a verdadeira realidade na execução desses princípios.

Conseguimos diferenciar projetos bem explícitos que até a década de 1970, serviram para nortear a Educação Indígena brasileira, projetos pautados na catequização e domesticação cultural, com a assimilação da cultura ocidental pelos indígenas que eram "integrados" culturalmente a sociedade brasileira. Dessa forma, as tradições indigenistas eram pautadas com a finalidade de estimular a economia e a sociedade indígena a uma subordinação e consequente dependência dos mecanismos de acumulação do capital.

Após a década de 1980, ocorreram mudanças no quadro, mas também ambiguidades, não houve grandes revoluções das práticas que conduziam os caminhos na Educação Indígena, as transformações ocorreram nas concepções que direcionavam a relação do Estado brasileiro e a realidade indígena. O período foi o marco da afirmação e de mobilizações organizadas por 
indígenas em todo Brasil, isso foi o estopim para dar início a mobilizações indígenas para conquistas políticas num país que por tradição tinha orgulho da democracia racial e invariabilidade linguística.

Com representações e organizações os ticunas foram mudando o cenário em que frequentemente não possuíam voz ao longo da história. Agora possuem representantes na sociedade, dessa forma, participam com associações organizadas em conformidade com as leis Constitucionais. Não são únicas as representações indígenas, mas ultimamente proporcionaram grandes avanços e conquistas para os indígenas em diversas comunidades.

Em particular na região do Alto Solimões atuam agentes sociais, membros das comunidades como representantes e líderes das comunidades que formam o Conselho Geral da Tribo Ticuna - CGT'T, outra representação significativa na educação é a organização Geral dos Professores Ticunas Bilíngues - OGPTB, também possuem presença na saúde com a Organização de Saúde do povo Ticuna do Alto Solimões - OSPTAS. Essas entidades tiveram expressão como representantes no complexo de etnias existentes na região, com grandes conquistas e avanços, inclusive na educação.

As políticas públicas implantaram na educação indígena um sistema de ensino diferenciado. A educação escolar indígena, que veio na esteira dos movimentos sociais indígenas e indigenistas, começa emergir na década de 1970, como nova maneira de pensar a educação, dando origem a formulação de uma educação escolar indígena como garantia de um direito constitucional a esses povos. Esse novo se caracteriza mediante a reafirmação das diversas identidades étnicas, com uma preocupação em recuperar memórias históricas, e valorizando as línguas e conhecimentos nativos, em conformidade com projetos sociais definidos de forma autônoma pelos povos indígenas. 


\section{A COMPLEXIDADE E A IMPORTÂNCIA NO REPASSE DA CULTURA: O IMAGINÁRIO TICUNA, OS MITOS E OS FENÔMENOS DA EDUCAÇÃO}

A complexidade da raça humana não está dissociada dos elementos que a compõem. Segundo Morin, (2001, p. 55) "todo desenvolvimento verdadeiramente humano significa o desenvolvimento conjunto das autonomias individuais, das participações comunitárias e do sentimento de pertencer à espécie humana”.

Neste sentido, compreendemos através da observação de que culturalmente para a criança ticuna, as primeiras experienciais da educação são promovidas pela família, entretanto, diversos pais não percebem a importância de sua participação no repasse cultural para a manutenção cultural. Entendemos que ninguém pode escapar há educação, assim indígenas ticunas também são detentores de uma forma educacional singular.

Nessa perspectiva Brandão (1995) em sua obra O que é Educação, menciona uma correspondência dos indígenas aos não indígenas brancos que ofertaram à escola dos brancos aos jovens indígenas.

Nós estamos convencidos, portanto, que os senhores desejam o bem para nós e agradecemos de todo o coração. Mas aqueles que são sábios reconhecem que diferentes nações têm concepções diferentes das coisas e, sendo assim, os senhores não ficarão ofendidos ao saber que vossa ideia de educação não é a mesma que a nossa. Muitos dos nossos bravos guerreiros foram formados nas escolas do Norte e aprenderam toda a vossa ciência. Mas, quando eles voltavam para nós, eles eram maus corredores, ignorantes da vida da floresta e incapazes de suportarem o frio e a fome. Não sabiam como caçar o veado, matar o inimigo e construir uma cabana, e falavam a nossa língua muito mal. Eles eram, portanto, totalmente inúteis. Não serviam como guerreiros, como caçadores ou como conselheiros. 
Ficamos extremamente agradecidos pela vossa oferta e, embora não possamos aceitá-la, para mostrar a nossa gratidão oferecemos aos nobres senhores de Virginia, que nos enviem alguns dos seus jovens, que lhes ensinaremos tudo o que sabemos e faremos deles, homens (BRANDÃO, 1995, p. 8-9).

O ato educacional para os indígenas ocorria pela oralidade, essa era a ferramenta que proporcionava todo repasse cultural. Os pais e idosos eram os principais responsáveis por educar os filhos, o momento do deslocamento para o roçado, aproveitavam o momento do trajeto para repassar os conhecimentos e práticas culturais, que eram transmitidas conforme as circunstâncias. Assim, durante a pesca ou por ocasião das caçadas, de geração em geração os conhecimentos eram transmitidos. O processo de ensino e repasse cultural estão ligados diretamente a essas práticas cotidianas.

Os filhos geralmente acompanhavam seus pais nos afazeres do dia a dia, assim estavam nas caçadas, durante as plantio e na colheita do roçado, no preparo de comidas, das bebidas e em festas tradicionais, também nas diversas danças típicas e na confecção do artesanato ticuna. Dessa maneira, aprendiam rapidamente a se tornarem independentes nos desenvolvimentos dos trabalhos. Aqui não estamos fazendo referência ao trabalho nos padrões do sistema capitalismo atual.

Nos relacionamentos sociais não havia espaços de violência ou repreensão individuais, tudo era ligava-se ao coletivo, também a solidariedade coletiva. Dessa forma as crianças e jovens indígenas ticunas eram direcionados com uma educação nativa e salutar da cultura.

Assim sendo, para uma maior profundidade e compreensão da riqueza proporcionada pela educação mítica precisamos entender um pouco mais o que se configura em um mito. Assim, recorreremos as origens etimológicas do termo mito, cuja 
raiz grega, múthos, indicando a ideia expressa exclusivamente pela oralidade. Um mito seria algo que possui fundamentos em uma determinada cultura ligado a uma realidade social. Assim focamos determinado assunto ou dialogo, em algumas estórias, ou fábulas. Efetivamente, na língua grega, o verbo muthe’o sugere exatamente o contar, assim, seria: narrar algo ligado a ficção. A definição presente no léxico grego elucida melhor a questão: nesse entendimento, os mitos poderiam ser estórias, apresentadas como histórias relacionadas as tradicionalmente a cosmologia e explicações sobrenaturais de determinado povo, com seus deuses, sua cultura, seus heróis, suas crenças religiosas, etc. $\mathrm{O}$ mito se configura em ficção popular, narrada como sendo histórias que realmente aconteceram. Em suas origens os indígenas ticunas possuem mitos como ponto comum, acreditam que os deuses mitológicos Yo’i e Ipi foram são os responsáveis para que corresse o aparecimento de todas pessoas, o desenho a seguir retrata algo nesse sentido.

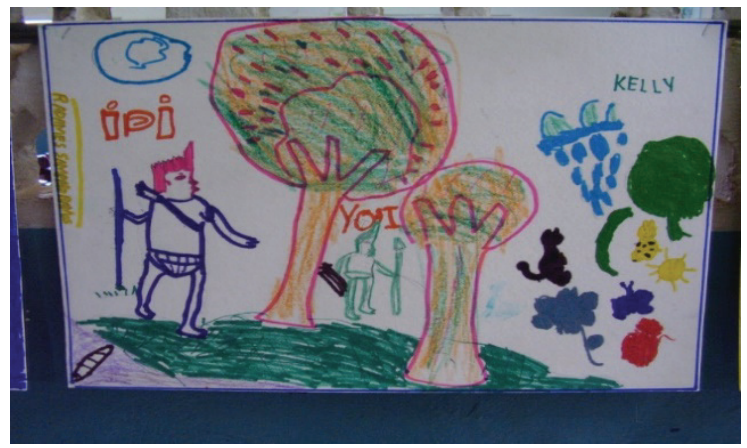

Figura 1 - deuses mitológicos Yo’i e Ipi Fonte: Arquivo pessoal do autor ${ }^{1}$

Culturalmente os ticunas em suas origens possuem de diversas histórias mitológicas geralmente "contadas" por idosos aos mais jovens e crianças. Essas histórias mitológicas possuem tendencia ilustrativa para retratar a vida na floresta amazônica, 
mostrando a responsabilidade social e dever cuidar do habitat natural como fonte que promove a vida. Com conhecimentos fundamentais proceder em ralação as caças, a pesca, a extração da madeira consumo consciente de produtos, visando o necessário ao cotidiano sob duras penas e castigo ou até maldições com feitiços caso haja desperdício que prejudique a natureza.

O legado mitológico era utilizado também para harmonizar os relacionamentos entre parentes os indígenas, ensinando mútuo respeito entre todos: aos filhos, aos pais, aos pajés, ao cacique e aos anciãos da tribo. Os mitos com suas inúmeras utilidades serviam ainda como mecanismos usados para promover a segurança tribal, com proteção e sentimento de pertencimento, motivando a coragem nos membros aldeias ticunas frente ao perigo eminente de ataques dos inimigos. Servia, também, como facilitador no contato com outros povos, assim, serviam também para educar como proceder em relação ao homem branco. A cosmo visão repassada através do ensino dos mitos revela a emergência da educação via escola para manter os conhecimentos tradicionais que estão se tornando obsoletos em muitas aldeias ticunas.

Os ticunas acreditam que ao olhar para a floresta, a aparência é que tudo está parado, mas no interior da floresta é diferente, dizem que a floresta tem espirito próprio que se movimenta constantemente; ela possui vida, castiga aqueles que a desrespeitam. O pé de Jenipapo, árvore nativa da Amazônia está presente em diversas situações e até no relato mítico que originou os povos. Os ticunas tem essas explicações como fundamento para a criação da espécie humana. Seus deuses mitológicos Yo’i e Ipi, e a jovem que surgiu do caroço do Umari, são os principais responsáveis atores para o aparecimento de todas pessoas.

A cultura dos ticunas possui diversas crenças que são riquíssimas para a educação cultural ticuna: eles acreditam que o fruto do jenipapo é um elemento indispensável para sua cultura. Assim, possuem o hábito de se pintarem com o jenipapo verde, para proteção da vida dos ticuna contra toda sorte de espíritos, 
contra males, e até doenças e também tem a capacidade de fechar o corpo, ou seja, dar uma proteção ao recém-nascidos e crianças.

O jenipapo serve para pintar o corpo nas ocasiões das festas e, do mesmo modo, quando ocorre a primeira menstruarão das meninas é necessário se pintar com o jenipapo e participar da festividade de inicialização denominada festividade da, assim chamada, moça nova. A festividade da moça nova foi narrada pelos ticunas no livro, organizado por Gruber (1997, p. 86), detalhadamente: “Quando uma menina fica moça, deve permanecer isolada, em uma casa dentro do mosquiteiro, em contato apenas com a mãe ou a tia. Enquanto a família prepara as bebidas e os moqueados. [...] quando já está tudo pronto, a festa pode começar".

Antigamente a festividade da moça nova era comunicado para os demais indígenas da região, com o pai da moça descendo o rio de canoa a remo e produzindo um sonido com um instrumento chamado aricana, feito exclusivamente para essa finalidade, era bem diferente dos dias atuais.

Dessa maneira, eles possuem uma cosmovisão diferente e muito enraizada em crenças e mitologias. Entendemos que os povos e culturas necessitam de explicações para as origens, da natureza e do ser humano e para explicar o futuro. Conforme Champlim (1991) existe uma grande necessidade essencialmente do ser humano que gera curiosidade, perguntas e dúvidas são geradas, e os seres impulsiona-se a procurar respostas a esses questionamentos.

Os ticuna explicam por meio de suas mitologias: no princípio o mundo era escuro, devido a gigantesca samaumeira, árvore que cobria toda terra, foi quando os deuses mitológicos Yo’i e Ipi, se juntaram a todos animais existentes na floresta resolveram derribar a grande sumaumeira, com muita dificuldade finalmente ela foi ao chão. Assim seu tronco originou no Grande Rio, em reverencia ao Rio Solimões, já os galhos deram origem a todos igarapés e lagos. 
Com a filosofia a história mítica passou por modificações na maneira de apresentar as ideias, assim que o mito cede espaço a análise da realidade. Começam surgir a explicação científica, com uma base empírica. Com o surgimento da ciência, o mitológico é confinado às estórias literárias de ficção, mesmo assim permanecem vivos em muitos lugares do mundo. Atualmente os indígenas não recebem a devida valorização, mesmo sendo fundamental para a manutenção da cultura dos indígenas ticunas.

Os diversos mitos sempre foram forças que impulsionaram os atos da humanidade. Os mitos referentes a deuses que dão galardão e castigam sempre encorajaram os homens para adotar determinadas atitudes na maneira de agir.

Os mitos possuem histórias e relatos que impressionam não são meras narrativas divertidas, mas o objetivo deles é sempre direcionando os homens a ações. O sistema mitológico continha histórias que explicavam tudo que aguçava a curiosidade dos homens, embora, embora não dispondo mecanismos para investigá-los cientificamente. É natural que os relatos mitológicos foram elaborados como verídicos, com esperança os seres povos acreditassem.

Conforme Champlim (1991) mostra que as consagradas ordens religiosas foram essencialmente mitológicas, consistindo em sistemas inventados através da grande imaginação humana. $\mathrm{O}$ autor segue argumentando:

[...] Desde os tempos de Platão, os filósofos precisavam ter extremo cuidado com o que diziam a respeito dos mitos encontrados nos escritos de Homero, mitos esses que se tornaram a base de religiões populares, politeístas. E isso porque negar os mitos sobre os deuses era, para os gregos, o que é hoje negar a Bíblia para os evangélicos fundamentalistas. Os escritos de Homero eram uma bíblia para os gregos, e todos eles pensavam que Homero não podia ter-se enganado. Em certo sentido, os mitos são buscas pela 
verdade, posto que mal orientadas. Muitos mitos contêm um certo cerne de verdade que, posteriormente, vem à superfície. As realidades finais impressionam-nos no mais íntimo do ser, e acabam por conferir-nos discernimento quanto à sua veracidade, mas, no processo, isso é distorcido e exagerado [...] (CHAMPLIM, 1991, p. 320).

De igual modo, sugiram os diversos os mitos dos ticunas, embora com essas concepções, a mitologia, não dá conta de expressar a realidade em todos aspectos. Entretanto, ao surgir explicações, o mito mostra-se extremamente resistentes, e podem persistir por longos períodos de tempo. Dessa forma, ao buscar a verdade, a mitologia entrincheira-se, parecendo aos homens mais difícil sacrificar crenças preciosas, que foram consagradas através dos tempos, ainda que estejam equivocadas. Os mitos possibilitam união e coerência aos grupos étnicos, já, a realidade cientifica pode ameaçar esse movimento de união. Somente de forma gradual será possível que a tradição incorpore a verdade sacrificando de forma paralela aspectos do mito.

Nas religiões, tanto nas primitivas como nas avançadas, existe a urgência de mitos. O elo do divino e as experiências pessoais somente podem ser efetivados conforme conceitos da mitologia. Nas civilizações da antiguidade, já havia a urgência da explicação das origens e diversas outras coisas que possuíam relação com a espiritualidade, assim, eram explicadas pelos mitos.

A finalidade dos mitos é narrar, de maneira histórica, as experiências humanas e a busca consciente pelo divino. Mente sentido entendemos as maneiras para explicações com mitos revelaram originalmente os grandes mestres da raça humana. Todavia, entendemos que esta afirmação seja passível de discussões e opiniões contrarias. Entendemos que centro das questões relacionas aos mitos referisse a religiosidade. Assim, nos mitos Ticuna existe o conceito do lugar sagrado, chamado 
Eware possivelmente o "paraíso", onde seus mortos ancestrais irão permanecem encantados.

Convicções de raiz animistas podem ser diretamente associadas forma ticuna de educar. $\mathrm{O}$ vocábulo animismo possui origem do lat. anima (alma, fôlego), conforme Champlim (1991), teria sido usado primeiramente por Stahl em 1720, se referindo a conceitos filosóficos da alma do Cosmo.

Os ticunas acreditam que existem espíritos em todos lugares, foi preciso nomear os espíritos protetores dos povos que viviam em sociedades, dessa forma, os ticuna atribuem diversas funções para os espíritos que são: proprietário, genitor, genitora da natureza, entre outros; segundo ensinamentos tradicionais descritos nas histórias do Livro da Árvore, dizem: "seres nós chamamos de nanatü, que sign. "dono", "pai” ou "mãe das árvores, dos animais, dos peixes, das águas. O buritizal tem dono, o açaizal tem dono, o seringal tem dono, o caranazal tem dono [...]" (GRUBER, 1997, p. 28).

O mito do Curupira faz parte da mitologia ticuna. Dizem que o curupira é o dono das florestas e sua residência é nas sapopembas das samaumeiras. O Curupira gosta de silêncio e vive sempre andando pela floresta. Quando está cansado, se senta no casco dos jabutis, que costumam emprestar no casco como assento, conforme os antigos o Curupira possui cabelos compridos, com corpo peludo, seus olhos são pretos e seus pés virados para trás. Relatam que é possível encontrar diversos tipos de curupiras: o pai das samaumeiras, o dono dos jabutis, o dono de diversos animais da floresta, os Curupiras machos e os Curupiras fêmea. Os Curupiras assustam os caçadores ao bater no tronco das árvores, atraindo as pessoas para colocar encanto. Mediante o ataque do Curupira, só existe uma opção que é matá-lo, batendo no nele com pedaços de paus podres, antes de morrer ele costuma dizer: "Se um dia eu me acabar, fica outro no meu lugar guardando tudo o que é meu". A figura do curupira sobrevive na memória das crianças da aldeia. Em 
uma oficina que realizamos nas aldeias na Escola O'i Thurune relacionado aos mitos e lendas, um dos alunos desenhou o curupira (que podemos observar na fig. 2), na figura o curupira com seus pés voltados para trás, com a finalidade de despistar o caçador. Acreditam que o curupira fez o caçador ir centro da floresta até se perder e desaparecer.

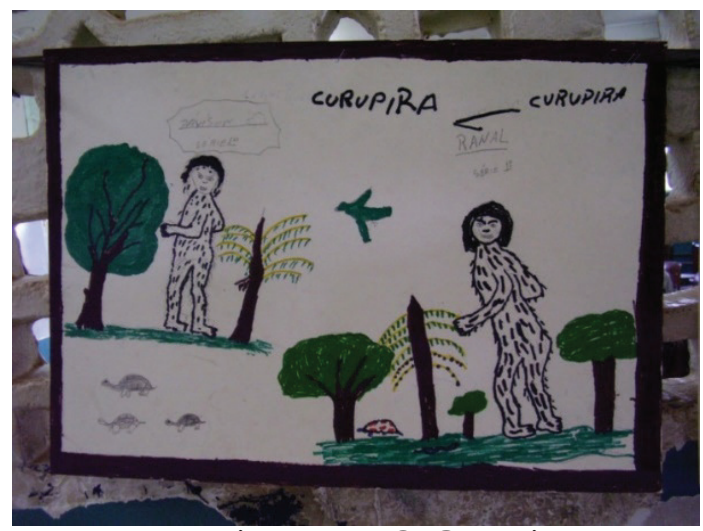

Figura 2 - O Curupira

Fonte: Arquivo pessoal

Descobrimos outro animal mitológico assustador que se chama Mapinguari, ele costuma atacar e vive a procura de caçadores mata a caça para o comercio e não somente para o consumo. $\mathrm{O}$ mito dos mapinguaris contribua na preservação das florestas e na conservação da harmonia familiar, pois acreditam que não devem caçar na floresta em feriados e domingos. Esse mito leva-nos a acreditar que, apesar da coerção e do medo, a coisa mais sabia é permanecer com a família e parentes na comunidade ticuna.

Conforme pesquisa na área da teologia, pode-se dizer que os encontros com qualquer uma dessas forças espirituais pertencem à esfera do "dinamismo". Causada por poderes ou habilidades espirituais superiores, garantindo que poucas pessoas tenham contato direto com certos espíritos, tornando a vida 
em comunidade com certa harmonia possível. Portanto, o pajé é a pessoa da tribo que é responsável por se mover no reino espiritual, intercedendo com o espírito para que eles possam realizar: colheita, prosperidade e trabalho imprevisível. Talvez a tarefa mais importante do pajé é chamar certos espíritos da floresta para curar. Doenças, picadas de cobras e outras condições adversas na vida diária do povo Ticuna.

Também podemos afirmar que o Pajé tem especial importância na nação Ticuna. As pessoas acreditam que ele tem o poder de curar, praticando o xamanismo, ele tem a capacidade de atacar inimigos gananciosos com feitiços, e a única pessoa que desfaz o feitiço é outro xamã, mas depende do grau de interação com os pajés. No entanto, algumas árvores usadas como materiais medicinais podem ser usadas por diferentes pessoas da tribo Ticuna, e não têm necessariamente o poder de pajé. Elas são chamadas de alquimia Tikuna, que em muitos casos cura o doente.

O povo Ticuna acreditam que as árvores têm espíritos, e esses espíritos ajudam no trabalho do pajé, porque apenas eles podem se comunicar com esses espíritos da floresta. $\mathrm{O}$ animismo ticuna distingue entre espírito e material, e reconhece a existência de forças sobrenaturais que afetam suas vidas por inteiro. Existem muitas maneiras de entrar em contato com essas forças diretamente relacionadas com a prática diária dos Ticuna. Encontramos alguns tabus no meio ticuna. O termo tabus vem da língua das ilhas do Pacífico, onde, segundo Champlin (1991), a proibição é aplicada como técnica de controle social, ou seja, um sistema de proibição e proibição bem elaborado. Violar o código de conduta do grupo, ou contatar qualquer coisa que seja proibida, significa uma infecção adquirida por indivíduos que ameaçam a si mesmo e a todos do grupo. A punição surge automaticamente da própria situação perigosa.

Podemos ter certeza de que muitas forças espirituais estão trabalhando ali, talvez alguma forma demonismo ou de pajelança. 
Na cultura Ticuna, a organização está mais interessada em purificar do que em punir criminosos, mas o poder invisível garante algum tipo de vingança contra os criminosos.

Alguns tabus são como encaram o sangue da mulher durante a menstruação ou no parto também é considerado perigoso e requer rituais de purificação. Os caçadores que retornaram após a caçada ou conflito são conhecidos por estarem maculados pela morte, precisam de um ritual de purificação. E também aqueles que violam o código de conduta sexual ou cometem crimes graves, como homicídio, praticam a quebra de tabus.

Alguns líderes e pajés são considerados pessoas sagradas e mágicas com uma aura sagrada e são "intocáveis" pelas pessoas comuns. Até as roupas e objetos usados por essas pessoas são considerados perigosos. Objetos e ferramentas religiosos adquirem esse poder, determinados alimentos são convenientemente proibidos. A palavra tabu tornou-se parte de muitas línguas, com um significado proibido e, por ser proibida, tornou-se mais atraente.

O conhecimento artístico de fazer e pintar máscaras está principalmente no domínio dos homens, que também são responsáveis pela maioria dos objetos e rituais, como alguns acessórios de uso, instrumentos musicais, reclusões e bastões esculpidos. Essa prática pode ser considerada um tabu, pois acredita-se que somente quando os homens da aldeia fazem certos itens é possível se comunicar com o mundo espiritual da floresta.

Por outro lado, as mulheres são responsáveis pelo transporte de alimentos, pois acredita-se que os homens podem resistir ao espírito e apenas as mulheres férteis podem realizar determinadas tarefas. As mulheres devem trazer os produtos quando voltam do campo, enquanto os homens costumam trazer tecidos ou deixar as mãos livres. Isso acontece porque acreditam que coisas inesperadas podem acontecer a qualquer momento, e a pessoa deve estar preparada para agir quando necessário. Para os ticunas, existem várias situações em que a educação cultural tradicional não pode ser realizada juntos, homens e mulheres, 
porque eles quebraram alguns tabus de manter e participar da proteção cultural.

\section{A COMPLEXA RELAÇÃO DA EDUCAÇÃO INDÍGENA E A EDUCAÇÃO ESCOLAR INDÍGENA}

A forma educacional presente na aldeia, não se configura um paradigma de educação indígena, mais sim uma educação escolar indígena, paradigma não indígena de educação, mesmo com os professores bilíngues, a escola se encaixa nos padrões da escola não indígenas. Nesse cenário de complexidade que surgem diversos problemas relacionados a deficiências na transmissão da cosmovisão ticuna, das crenças e consequentemente relacionasse a aspectos que podem interferir nas técnicas de ensino e aprendizagem dos indígenas.

Os indígenas mais antigos depositavam enorme valor na transmissão cultural, ao imaginarem que seria perpetuado por meio do aprendizado nas escolas, com pedagogias específicas e direcionadas a aquisição e conservação cultural dos ticunas. Entretanto, o que estão presenciando são enormes mudanças a ponto de expressar segundo Oliveira (2012, p. 49) "o mundo de hoje é outro mundo, é outra vida, e bem diferente do que pensávamos e sonhávamos". Foi o que disse um indígena, que nasceu em 1944, e presenciou de perto as grandes mudanças sociais ocorridas sob o discurso de grandes avanços. Eles têm pagado o preço a perda de várias formas e procedimentos da cultura ticuna, que frequentemente são minados ao absorverem modos e costumes da culturais dos não indígenas. Nesse sentido, Weigel (2000) relata que precisamos analisar os resultados da educação escolar nos aspectos da gradativa dessacralização de aspectos importantes do cotidiano na aldeia, estabelecida com a racionalidade que desvincula o sagrado e o profano, entre os homens e os deuses, entre os homens e a floresta.

Partindo dessa perspectiva, a oferta de educação nas aldeias, mesmo se tratando de educação não-indígena, também pode 
contribuir significativamente para o desenvolvimento e preservação cultural dos ticunas. Para tanto, os professores precisam se envolverem métodos e estar comprometidos profissionalmente para que ocorra a preservação motivada pelos educadores. Freire (1997), menciona que o aprender deve incluir e ir além da simples noção de escolarização. "A escola é apenas um local importante no qual ocorre a educação, no qual homens e mulheres tanto produzem, como são produtos de relações sociais e pedagogias específicas" (FREIRE, 1997 p. 48), O autor entende que a educação deve ser a prática da liberdade, diferente da prática da dominação, que implica exatamente em negar o homem abstrato e tê-lo como isolado, solto, e desvinculado do mundo.

Nesse viés, a aprendizagem torna-se procedimentos de aquisição e assimilação, consciente que agrega com novas formas e padrões de perceber o mundo, de ser, de pensar e agir, com esse mecanismo a aprendizagem e o ensino começam a caminhar juntos, um influenciando diretamente no progresso do outro. Assim, Piletti (2003 p. 33) destaca que "há uma relação intrínseca entre o ensino e a aprendizagem não há ensino se não há aprendizagem, é necessário conhecer o fenômeno sobre o qual, o ensino atua que é a aprendizagem".

O paradigma educacional implantado nas aldeias tem demostrado uma fragilidade ficando evidente que a forma educacional denominada de educação escolar indígena, mesmo sendo bela teoricamente, mas se apresenta ineficaz na aplicabilidade do cotidiano ticuna, sendo que a nação ticuna ao progredir, necessitam de uma forma educacional que contemple o dia a dia e valorize a forma cultural dos ticunas em sua totalidade. Segundo Jaeger (2001). Dessa forma, os povos conseguem atingir determinadas conquistas no desenvolvimento, e sentem-se de forma natural inclinado a praticas educacionais.

Ainda assim, o sistema educacional implantado nas comunidades indígenas não abarca as aspirações culturais dos ticunas, mesmo que existam políticas públicas direcionadas 
para uma Educação Escolar Indígena, nas últimas décadas, e formuladas partindo da Constituição Federal 1988, passando a legitimar novos paradigmas do Estado brasileiro em relação as etnias indígenas, valorizando a socio diversidade dos indígenas. Contudo, percebemos que ainda não é ofertada uma educação que preencha o ideal imaginário dos ticunas.

As escolas presentes na aldeia atualmente, não é a sonhada pelos antigos no passado; a vida se tornou difícil e diferente para os ticunas, os que viveram em outro momento histórico sonhavam com uma forma educacional que ajudasse a preservar as tradições culturais. A Educação implantada nas aldeias não se preocupa com a manutenção e preservação cultural, mas tudo concorre a preparar os indígenas para integração na sociedade não indígena.

A Educação na aldeia passou a ter como referencial o sistema de ensino formal, com bases na escola e no letramento, das instituições com características não indígena. Devemos considerar, assim, as formulações executadas até o momento se configuram Educação Escolar Indígena, mas não é uma Educação Indígena em sua essência. Esta última é baseada no conjunto e formas diversas de socialização transmitindo os conhecimentos peculiares e comuns da cultura nativa. $\mathrm{Na}$ culturalidade e tradição ticuna, a aprendizagem era pensada visando a formação para toda vida e essa forma educacional passava pelo repasse das mitologias, das crenças e tabus existentes.

Neste sentido, o pensamento de Edgar Morin (2001) envolvendo a complexidade, nos auxilia ao pensar uma educação do futuro das comunidades ticunas, assim no livro os 7 saberes necessários para a Educação do Futuro de Morin (2001) nos incomoda, para a fim de ensinar as gerações a aprender a aprender, e assim vamos construir um maior projeto educacional e que tenha utilidade, um projeto de dimensões planetárias. A educação é essencial à compreensão humana em todos os níveis e segmentos. 
Como formadores de opinião devemos fazer uma mudança primeiramente em nós colocando em prática os princípios necessários a educação para o futuro que segundo Morin (2001) são: As Cegueiras do Conhecimento: o Erro e a Ilusão, que fala da cegueira e que a educação conduz o conhecimento; Os princípios do Conhecimento Pertinente, que são as informações essenciais que os ticunas precisam saber sobre o mundo, e devem ser contextualizadas com os conhecimentos do mundo ocidental e do mundo ticuna; o Ensinar a Condição Humana, onde o Morin esclarece que a educação para o futuro, se faz mediante o ensino voltado aos conhecimentos do humano, como parte do universo; o Enfrentar as Incertezas, as incertezas históricas vividas durante os séculos; Ensinar a Compreensão, onde relata o problema da compreensão humana; A Ética do Gênero Humano, que evidencia claramente a inseparabilidade do gênero humano como a trilogia indivíduo/ sociedade/espécie.

Dessa forma ao disseminar esses conhecimentos possamos realizar uma ressignificação em nós, em nossa pratica pedagógica, motivando as mudanças necessárias à sociedade. Edgar Morin (2001) nos motiva a fazer coisas novas, coisas possíveis, ser éticos, conhecimento comprometido objetivando a busca pela identidade terrena. Entendemos que o legado de Morin, (2001) seja um direcionamento e uma possibilidade para a educação dos indígenas ticunas e a complexidade de uma nova forma de educação no Sec. XXI.

\section{CONSIDERAÇÕES FINAIS}

O paradigma dito tradicional da educação indígena ticuna, não consegue concorrer com o sistema esmagador e influente que pertence a cultura não indígena. As principais formas dessa influência ocorrem mediante o contato com os não indígenas (sobretudo nas relações comerciais) e o sistema de comunicação em massa, através dos programas de TV. Entendemos que diversos conhecimentos da cultura poderiam até serem ensina- 
dos pelos pais, todavia, os jovens indígenas são influenciados com a civilização dos não-indígenas e estão adquirindo outros hábitos no cotidiano. Isso resulta em uma barreira no repasse cultural entre as várias gerações que pode ocasionar uma perda na identidade cultural dos Ticunas.

A escola recebe e assume uma função que tradicionalmente era dos pais. O professor agora assumi a grande responsabilidade com a educação de alunos indígenas, e, no entanto, ainda são vistos pela grande parte dos pais, como os principais responsáveis pelos resultados não obtidos, em geral os pais não se dão conta que devem exercer influência na composição cultural e religiosa de seus filhos. Dessa forma, a escola acaba precisando ir além, preenchendo a lacunas deixadas pelas legislações e pela a sociedade.

Dessa forma, compreendemos que para a sonhada educação escolar indígena alcançar bons resultados no século XXI é preciso ressignificar as instituições escolares, cujo modelo historicamente reforça a negação da grande diversidade sociocultural, a escola precisa ser transformada em espaço que sejam construídas relações interétnicas direcionadas a manter a pluralidade cultural, utilizando diversas concepções pedagógicas que garanta aos povos indígenas como sujeitos de direitos e deveres.

\section{REFERENCIAS}

BRANDÃO, Carlos Rodrigues. O que é educação. Editora. 33. ed. Brasiliense, São Paulo, SP, 1995.

CHAMPLIN, Ph. D. Russel Norman. Enciclopédia de Bíblia Teologia e Filosofia. Editora Candeia, São Paulo, SP, 1991.

FREIRE, Paulo. Pedagogia do oprimido. 4. ed. Terra e Paz, Rio de Janeiro, 1977.

GRUBER, Jussara Gomes. (Org.). O livro das árvores. Benjamin Constant: OGPTB, 1997.

JAEGER, Wermer Willhelm. Trad. Artur M. Perreira. Paidéia a formação do homem grego. 4. ed. São Paulo: Martins Fontes, 2001. 
OLIVEIRA, Samuel Rocha. O Processo Educacional da Cultura Indígena Ticuna na Região do Alto Solimões. Dissertação de Mestrado, São Paulo: PPGE Programa de Pós-Graduação em Educação, UMESP, 2012.

LÉVI-STRAUSS, Claude. Raça e história. In: Antropologia Estrutural II. Rio de Janeiro, Tempo Brasileiro, 4ª . ed. 1993.

MORIN, Edgar. Os Sete Saberes Necessários à Educação do Futuro. $3^{\mathrm{a}}$ ed. São Paulo: Cortez, Brasília, 2001.

PILETTI, Claudino. Didática Geral. 23. ed. São Paulo: Ática, 2003.

WEIGEL, Valeria. Escolas de branco em malokas de índio. Editora da Universidade do Amazonas. Manaus, 2000. 